\title{
Tackling a complex problem via a novel approach: Decision analysis may improve quality of life for patients with anomalous aortic origin of a coronary artery
}

\author{
Travis J. Wilder, MD, ${ }^{a}$ and William G. Williams, $\mathrm{MD}^{\mathrm{b}}$
}

\author{
From the ${ }^{\mathrm{a} D e p a r t m e n t}$ of Surgery, University of California San Diego, San Diego, Calif; and ${ }^{\mathrm{b}}$ Congenital Heart \\ Surgeons' Society Data Center, The Hospital for Sick Children, Toronto, Ontario, Canada. \\ Disclosures: Authors have nothing to disclose with regard to commercial support. \\ Received for publication Aug 26, 2016; accepted for publication Aug 26, 2016. \\ Address for reprints: Travis J. Wilder, MD, University of California San Diego, 200 W. Arbor Drive, \#8220, San \\ Diego, CA 92103 (E-mail: twilder@ucsd.edu). \\ J Thorac Cardiovasc Surg 2016;152:1376-7 \\ $0022-5223 / \$ 36.00$ \\ Copyright (C) 2016 by The American Association for Thoracic Surgery \\ http://dx.doi.org/10.1016/j.jtcvs.2016.08.055
}

In this issue of the Journal, Mery and colleagues ${ }^{1}$ from Texas Children's Hospital use decision analysis methodology to investigate the optimal management strategy of young patients with an anomalous aortic origin of a coronary artery (AAOCA). As the authors mention, developing evidenced-based guidelines for the management of patients with AAOCA is challenging, in part, because of the rarity of the disease. ${ }^{2,3}$ Although a handful of large postmortem reviews have reported the incidence of sudden cardiac death (SCD) associated with AAOCA among young individuals, ${ }^{4,5}$ our overall understanding of the natural and "unnatural" (surgical) history of AAOCA remains limited because of a lack of large prospective reviews. ${ }^{2,6}$ Consequently, commonly accepted management strategies, such as exercise restriction, are largely based on anecdotal reviews or single-center experiences. Furthermore, the low prevalence of AAOCA makes a randomized control trial comparing management strategies unlikely. ${ }^{3}$

Mery and colleagues ${ }^{1}$ used independent decision analysis models for an anomalous left coronary artery and for anomalous right coronary artery from the opposite sinus of Valsalva (Figure 1) to evaluate life expectancy and quality of life assuming 1 of 3 hypothetical management strategies: (1) observation without exercise restriction, (2) exercise restriction, or (3) surgical intervention. Results from the decision analysis models demonstrated that for patients aged less than 30 years and more than 10 years with anomalous left coronary artery, surgery was associated with improved survival. Likewise, observation was found to be the preferred strategy for patients aged more than 30 years, for whom the perceived risk of SCD was lower than average, or for patients in whom the risk of perioperative mortality was higher than average (assumed to be $0.5 \%$ ). For patients with anomalous right coronary artery, observation

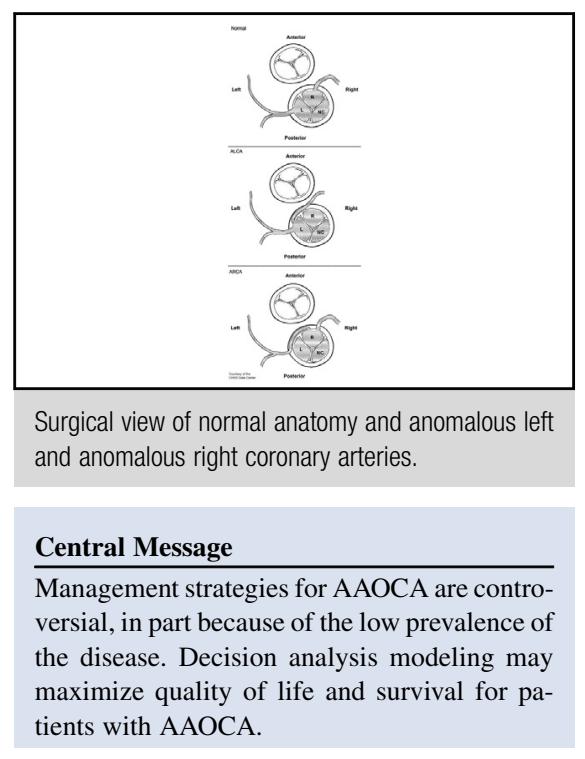

See Article page 1366.

seemed to be the preferred strategy. In terms of life expectancy, observation and surgery were similar. However, quality of life was superior with observation alone, except for patients aged less than 30 years with a high risk of SCD. An important and interesting finding by Mery and colleagues ${ }^{1}$ was that exercise restriction was the least preferred management strategy for almost all patients with AAOCA.

The finding that exercise restriction was a suboptimal strategy is in contrast to what is reported in clinical practice, where exercise restriction or avoidance of competitive athletics is often recommended without consideration of the anatomic subtype. ${ }^{3,7}$ As Mery and colleagues ${ }^{1}$ note, the impact of restricting the activity of young athletes may be associated with a significantly decreased quality of life. Therefore, suggesting that exercise restriction is an inferior management strategy for almost all patients with AAOCA is an important finding that may have important implications for developing guidelines on how to manage young patients with AAOCA.

Mery and colleagues ${ }^{1}$ are to be commended on making use of an innovative strategy to address a 
Normal
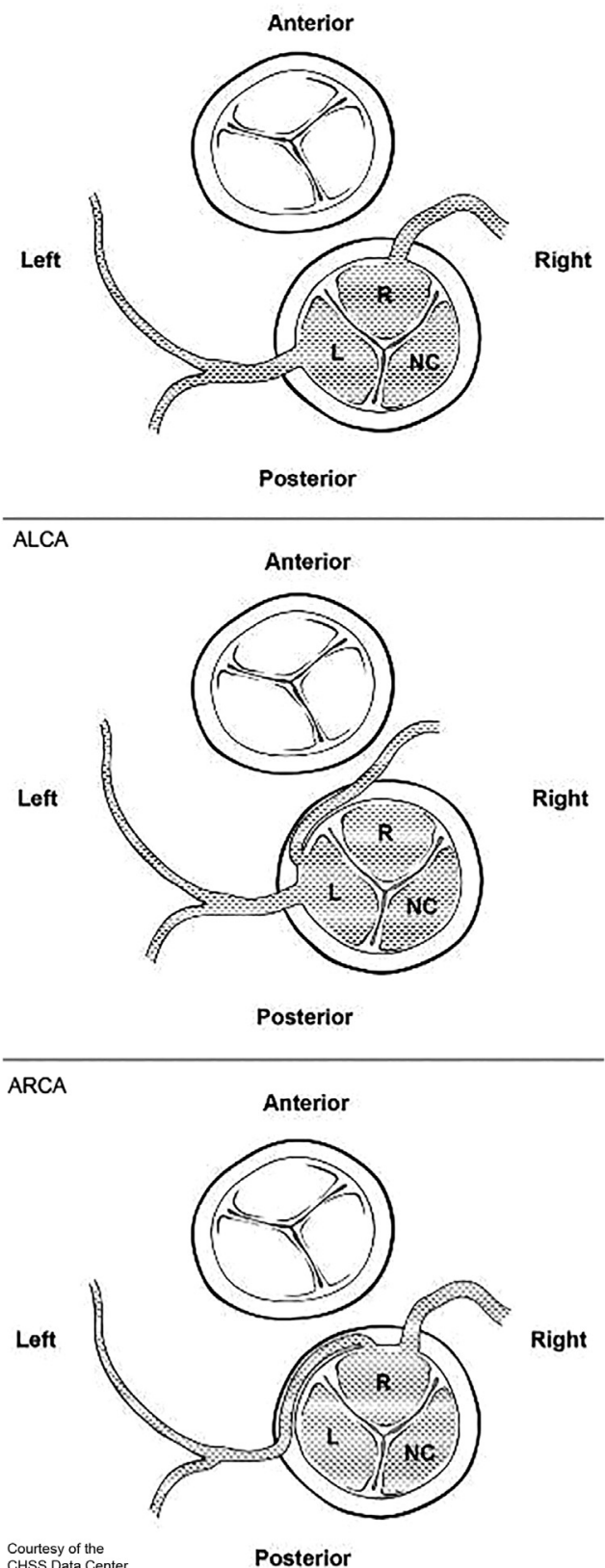

Courtesy of the
CHSS Data Center

Posterior

FIGURE 1. Coronary artery anatomy from the surgeon's perspective for: (1) normal coronary anatomy (Normal), (2) an anomalous left coronary artery from the right coronary sinus (ALCA), and (3) an anomalous right coronary artery from the left sinus (ARCA). (Figures provided courtesy of the Congenital Heart Surgeons' Society Data Center. Available at: http:// www.chssdc.com/content/aaoca-anomalous-aortic-origin-coronary-artery.) difficult clinical problem. Fundamental challenges in generating evidence-based guidelines within congenital heart surgery are related to the relative rarity of lesions and their broad spectrum of morphologic variation. Specifically, the diversity of anatomic lesions, low prevalence of any single lesion, and array of management strategies make it difficult for a single institution to determine the optimal strategy for a given lesion. To address these challenges, the Congenital Heart Surgeons' Society established the Data Center, a multi-institutional research database, created to develop guidelines for the diagnosis and management of patients with congenital heart disease. The AAOCA registry, as noted by Mery and colleagues, ${ }^{1}$ was created to help address the current lack of evidence-based managing for patients with AAOCA. ${ }^{8}$ Although analyses of large multi-institutional registries ultimately may guide management strategies for patients with AAOCA, defining the natural and unnatural history of AAOCA is certain to take years of patient follow-up. In the short-term, however, we must rely on methodology, as demonstrated in this study, to help us define the optimal treatment strategy for this lesion.

\section{References}

1. Mery CM, Lopez KN, Molossi S, Sexson-Tejtel SK, Krishnamurthy R, McKenzie ED, et al. Decision analysis to define the optimal management of athletes with anomalous aortic origin of a coronary artery. J Thorac Cardiovasc Surg. 2016;152:1366-75.e7.

2. Davis JA, Cecchin F, Jones TK, Portman MA. Major coronary artery anomalies in a pediatric population: incidence and clinical importance. J Am Coll Cardiol 2001;37:593-7.

3. Brothers J, Gaynor JW, Paridon S, Lorber R, Jacobs M. Anomalous aortic origin of a coronary artery with an interarterial course: understanding current management strategies in children and young adults. Pediatr Cardiol. 2009; 30:911-21.

4. Eckart RE, Scoville SL, Campbell CL, Shry EA, Stajduhar KC, Potter RN, et al Sudden death in young adults: a 25-year review of autopsies in military recruits. Ann Intern Med. 2004;141:829-34.

5. Maron BJ, Doerer JJ, Haas TS, Tierney DM, Mueller FO. Sudden deaths in young competitive athletes: analysis of 1866 deaths in the United States, 1980-2006. Circulation. 2009; 119:1085-92.

6. Brothers JA, Gaynor JW, Jacobs JP, Poynter JA, Jacobs ML. The Congenital Heart Surgeons' Society Registry of Anomalous Aortic Origin of a Coronary Artery: an update. Cardiol Young. 2015;25:1567-71.

7. Poynter JA, Williams WG, McIntyre S, Brothers JA, Jacobs ML. Congenital Heart Surgeons Society AWG. Anomalous aortic origin of a coronary artery: a report from the Congenital Heart Surgeons Society Registry. World J Pediatr Congenit Heart Surg. 2014;5:22-30.

8. Brothers JA, Gaynor JW, Jacobs JP, Caldarone C, Jegatheeswaran A, Jacobs ML, Anomalous Coronary Artery Working Group. The registry of anomalous aortic origin of the coronary artery of the Congenital Heart Surgeons' Society. Cardiol Young. 2010;20(Suppl 3):50-8. 